\title{
Trasplantes del espíritu: folclor y lengua nacional en Rodolfo Lenz
}

\author{
Pablo Concha Ferreccio* \\ Universidad de Chile, Chile
}

\begin{abstract}
Resumen
En este trabajo se examinan las implicancias ideológicas y culturales de la labor folclórica de Rodolfo Lenz. Nuestra premisa es que, a partir de la noción de archivo, el interés del filólogo por los estudios folclóricos opera como una estrategia para refundar y modernizar una idea de nación con medios positivistas. En una primera etapa, Lenz busca en estos materiales un núcleo cultural auténticamente chileno; más adelante, sin embargo, sus innovaciones en el ámbito de la enseñanza de lenguas lo llevan a relativizar este supuesto y a proyectar sobre el folclor una idea de legitimidad dada por el estilo. Nuestra tesis es que, producto de este tránsito, es posible derivar un sistema de la lengua nacional cuyo espacio articulador sería la escuela: allí se modela un estilo de expresión (derivado del folclor) en que dialogan, no sin tensiones, la lengua vulgar y la lengua literaria.

Palabras clave: Rodolfo Lenz, ideologías lingüísticas, folclor, lengua nacional, chilenidad.
\end{abstract}

* Para correspondencia, dirigirse a: Pablo Concha Ferreccio (pabloconchas@gmail.com). 
TRANSPLANTS OF THE SPIRIT:

FOLKLORE AND NATIONAL LANGUAGE IN RODOLFO LENZ

\begin{abstract}
This article examines the ideological and cultural implicances of Rodolfo Lenz's folklorical investigations. Our premise is that, from the notion of archive, his interest in folklorical research functioned as a strategy to refund and modernice an idea of nation through positivist means. In a first phase, the philologist scrutinized these materials searching for an authentically chilean kernel. Nevertheless, in a second stage, his innovations regarding language teaching made him relativize that approach and move to one based on folklor's legitimacy. Our thesis is that from this point it is possible to draw a system for the national language, whose articulating space would be the school: this institution shapes a style of expression (derived from folklore) by establishing a dialogue, not without friction, between the popular language and the literary language.
\end{abstract}

Keywords: Rodolfo Lenz, linguistic ideologies, folklore, national language, Chilean condition.

Recibido: 18/08/18 Aceptado: 05/03/19

El centro del pensamiento mismo debe tener cierta independencia del centro lingüístico, o de los diversos centros lingüísticos, si hablamos varios idiomas. Me lo figuro algo semejante a una máquina de escribir en que, oprimiendo un boton, se cambia el color de la escritura. En cuanto a mí, a menudo me sucede, que, si en un discurso en frances cito algunas palabras de ingles, contínuo la oracion en la segunda lengua

[...] aunque a la primera palabra noto el error i me rectifico: es como si hubiera escrito la cita con la cinta lacre i me hubiera olvidado volver a la negra. (Lenz 1918: 226)

¿Cuál es el objeto de toda instrucción superior? Convertir al hombre en una máquina. - ¿Qué medios hay que emplear para ello?. - Enseñar al hombre a aburrirse.- ¿Cómo se consigue esto?. - Con la noción del deber. - ¿Qué modelo debe proponerse? - El filólogo, que enseña a trabajar sin descanso. - ¿Cuál es el hombre perfecto? - El funcionario del Estado. ¿Cuál es la filosofía que da la fórmula superior para el funcionario del

Estado? - La de Kant: el funcionario como cosa en sí, colocado sobre el funcionario como apariencia. (Nietzsche 1968: XXIX) 


\section{PRELIMINARES ${ }^{1}$}

Desde hace unos quince años se viene experimentando un renovado entusiasmo de lingüistas, literatos y cientistas sociales por la obra y la figura de Rodolfo Lenz. Así, se ha abundado en el carácter, implicancias e importancia histórica de sus pesquisas para diversas subáreas de la lingüística (gramática, lexicografía y enseñanza de idiomas) y la antropología. En este segundo ámbito, se suele destacar su rol como fundador de los estudios folclóricos en Chile, con énfasis en la producción referida a la lengua y cultura mapuches, mientras que la dedicada al folclor chileno se ha reservado casi exclusivamente a un interés patrimonial ${ }^{2}$. Este texto pretende aportar entonces a la consideración crítica del folclor chileno según lo pensó Lenz, para leer desde allí una propuesta sobre la "lengua patria" o "nacional". El interés que nos guía es sobre todo, pues, culturalista.

Respecto de nuestros objeto y corpus, se debe notar que aun cuando el autor establece con claridad el asunto de cada texto, muchas veces desarrolla un diálogo entre sus objetivos pedagógicos y sus hallazgos científicos en relación con el destino nacional; de ahí que nuestro estudio considere no solo los trabajos dedicados mayor o solamente a materias folclóricas, sino también otros en que deslizó observaciones de tal naturaleza ${ }^{3}$. En una palabra, más que como un contenido separado de otros, comprendemos lo folclórico como una de las dimensiones culturales que interesaron a Rodolfo Lenz en sus múltiples ocupaciones.

A partir de la unidad de Lenz como lingüista (cf. Ferreccio 1979: 10), se pueden delimitar dos áreas de desempeño distintas que obedecen, a su vez, a dos interpelaciones ideológicas: la del Estado, que mueve a Lenz en tanto

1 Parte de este trabajo fue presentada en el Tercer Congreso Latinoamericano de Glotopolítica, Leibniz Universität, Hannover, 27-30 de septiembre de 2017. Agradezco los comentarios que Darío Rojas y Juan Antonio Ennis hicieron a una versión previa de este artículo. Los bemoles que persisten son, por supuesto, de mi exclusiva responsabilidad.

2 Acerca de Lenz y la cultura mapuche, véase Sánchez 1992 y Pavez 2015; en la misma línea, véase Payàs 2015 sobre el problema de la traducción mapuche-español. Por otra parte, con "interés patrimonial" nos referimos al carácter de guía que ha tenido la obra del alemán para los más importantes folcloristas posteriores, como Yolando Pino, "connotado discípulo" (Contreras 1989: 48), y Manuel Dannemann (cf. 1989-1990; 2010), fundador de la revista Archivos del Folclore Chileno.

3 Es probable que ello se deba a que: "La variada gama de sus producciones [...] son, en verdad, la manifestación de una muy específica unidad teórica y práctica de su excluyente profesión de lingüista" (Ferreccio 1979: 10). 
pedagogo y agente estatal que reflexiona sobre política idiomática con un objetivo reformador; y la de la ciencia, que lo mueve en tanto investigador o científico, representante en América Latina de la lingüística moderna ${ }^{4}$. Así, mientras su rol de agente estatal lo lleva a ver la lengua en sus diferentes variedades y contactos (sobre todo, la lengua vulgar), su interés científico se vierte principalmente en labores de recolección y análisis del folclor. Aquí queremos sugerir que se trata de dos caras de la misma moneda y que, por tanto, puede ser provechoso entender un área y su objeto desde y con la otra y su objeto correspondiente. El mismo Lenz establece esta distinción al hablar de sus "ocupaciones obligatorias" u "oficiales" en la pedagogía frente a sus "estudios predilectos, la filolojía románica i la lingüística en jeneral" o bien "el estudio sistemático del dialecto vulgar chileno" (1918: 204): las esferas del deber y del deseo ${ }^{5}$.

En sintonía con un nacionalismo de nuevo cuño, que rescataba la dimensión étnica y que se vinculaba con unas capas medias ilustradas descontentas con el tipo de vínculo social que caracterizara la sociabilidad oligárquica del siglo XIX (Subercaseaux 2007: 26-28), Lenz se dio a la tarea de formar un archivo nacional recogiendo y generando documentos que venían de la tradición folclórica otrora desdeñada ${ }^{6}$. En su función de

4 Con el término "agente estatal" no buscamos designar a Lenz como un representante fiel de este o aquel programa político (más allá del liberalismo finisecular), sino enfatizar sobre todo uno de los campos de acción de su práctica y la correspondiente responsabilidad que le cabe en los mismos, es decir, su actuación como profesional de la lengua en la formulación de políticas lingüísticas que se implementan en el aula escolar o universitaria. En este sentido, cabe destacar que su mayor lealtad se refiere a la ciencia, única garante de su independencia intelectual: "Sin dejar nunca el lugar lúcido y extrañado del extranjero, Lenz brega por un espacio relativamente autónomo para su práctica, el de una gramática descriptiva, científica y no prescriptiva y punitoria, procurando [...] convertirse no ya en vocero del Estado, sino en un interlocutor válido para intervenir, ahora sí, sobre las políticas de la lengua legítima en el espacio de su producción, la escuela". (Ennis 2016: 142)

5 Pruebas de tal distinción se hallan en la carta a Rufino José Cuervo del 20 de julio de 1896: "Por desgracia las ocupaciones con la lengua de los indígenas no me han dejado concluir varios trabajos principiados con motivo de mis clases de castellano en el Instituto Pedagógico" (cit. en Schütz 1976: 543). Luego, en el Diccionario: "Desde que llegué a Chile, en 1890, he dedicado todo el tiempo que me dejaban mis ocupaciones obligatorias en la enseñanza superior i secundaria, a la continuacion de mis estudios predilectos, la filolojía románica i la lingüística en jeneral" (1979 [1905-1910]: 22); más adelante aún, en carta a Julio Saavedra Molina: "Cuando en 1890 me habia hecho cargo de mis cátedras en el Instituto Pedagógico de Santiago, comprendí luego que sería una tarea científica interesante el estudio sistemático del dialecto vulgar chileno. Resolví, pues, dedicarle todo el tiempo que me dejarian disponible mis ocupaciones oficiales". (1918: 204)

6 Para un tratamiento comprensivo y lúcido de la empresa archivística de Lenz, véase Ennis 2016 y Ennis y Pfänder 2013. 
arconte o guardián de tal archivo ( $c f$. Derrida 1997), veló por la constitución e interpretación de los signos que lo componían y reguló su economía de acuerdo con los poderes que la institución le dispensara (en este caso, el Estado $)^{7}$. En un momento de crisis y modernización generalizada de las formas de vida nacionales y de sus referentes y valores, este archivo serviría de herramienta para la invención de tradiciones que pretendían despertar un nuevo tipo de identificación de los ciudadanos con la nación moderna ( $c f$. Hobsbawm 2002: 8-9). Las prácticas investigativa (lingüístico-etnológica) y profesional (pedagógico-política) de Lenz pueden entenderse como inscritas en el proyecto mayor de refundar la idea misma de la nacionalidad chilena.

El potencial político del archivo que elaboró Lenz puede ser calibrado a partir de la noción de autenticidad (Echtheit). En efecto, sobre ella se habían fundado en el siglo XIX los estudios folclóricos en Alemania, cuya búsqueda era ante todo emocional y moral (Bendix 1997: 5-7). Sin embargo, incluso antes de que la figura filológica del archivo, de un depósito que guarda la memoria y el "origen" de una comunidad, se vinculara con la explotación colonial de las potencias occidentales (Errington 2008: 1), la idea de una operación restaurativa había nacido ya junto con otra, la pedagógica, anudadas ambas a la de transmisión. La fidelidad de la transmisión había sido la principal preocupación de los gramáticos alejandrinos cuando quisieron volver accesible el texto homérico a los lectores instruidos del siglo III a. C., abocándose al establecimiento de versiones que recuperaran el sentido original de los textos del pasado (Reynolds y Wilson 1986: 21-27). A fines del siglo XIX, al mismo problema de la autenticidad de los materiales y de las versiones se enfrentó Rodolfo Lenz (como científico y como pedagogo) cuando leyó las poesías populares que circulaban por las calles de Santiago o cuando lo sorprendió el canto de una cueca agreste. ¿Cómo transmitirlos de manera fiel? ¿A qué tratamientos someterlos? ¿De qué manera presentarlos a los diferentes públicos?

Para comenzar a responder estas preguntas, vale la pena esbozar el lugar de enunciación de Lenz. La perspectiva de Lenz como un sujeto ubicado en un entrelugar nos permite desconsiderar tanto un posible reclamo de fidelidad a los cuerpos teóricos heredados como cualquier pretensión de unidad respecto a su actuar político. Las negociaciones, las tensiones no

Lenz llega a Chile en 1890, junto con otros seis profesores alemanes, para dictar las cátedras de inglés, francés e italiano en el recién fundado Instituto Pedagógico. En 1903 dejó la de inglés y tomó la de Gramática moderna, y en 1919, al morir el profesor Federico Hanssen, se hizo cargo también de Gramática histórica. Para informaciones biográficas, véanse Gutiérrez 1920 y Escudero 1963. 
enteramente resueltas, las paradojas y aporías, son una parte constitutiva del entrelugar en tanto espacio de enunciación inestable que redefine sus coordenadas estratégicamente ${ }^{8}$. En ese sentido, en la obra de Lenz, la relación entre las variedades de lengua también se vincula con las condiciones de autenticidad o legitimidad del folclor; más aún, en la base de esa relación se hallan ideas lingüísticas que varían según el momento que se enfoque y el punto de vista que se examine: el del científico o el del pedagogo. Estos cruces podrían ayudar a entender no solo lo que Lenz entiende por cultura nacional, sino también de qué forma se ubica e incide en ella desde distintas esferas de la praxis lingüística. Como han ponderado Ennis y Pfänder: "Su labor no supone sencillamente la instalación sin más de la mirada colonial para dar forma a la materia americana, sino que se inserta desde allí en su tradición para renegociarla e instalar un lenguaje" (2013: 147).

En la primera parte de este ensayo revisamos las obras de Lenz dedicadas al folclor chileno para describir su postura frente a la autenticidad, con especial atención a los conceptos de resto y Sprachgebäude; en la segunda, nos concentramos en los cambios que sufre su concepción del folclor por influjo de ideas pedagógicas (entrada del folclor en la escuela); en la tercera, por último, vinculamos lo anterior con el problema del estilo y la cultura chilena. Tal estilo sería una de las bases de la idea de Lenz sobre la lengua nacional, al servir como puente entre el lenguaje vulgar y la lengua literaria.

8 La noción de entrelugar fue acuñada por el brasileño Silviano Santiago (1971) para pensar la particularidad de las culturas coloniales desde el problema acerca del original y la copia que signa la relación entre centros y periferias. Inscrita en una línea de pensamiento deconstructivista, la propuesta de Santiago es dejar de pensar los intercambios culturales desde la influencia (unidireccional, jerárquica), para en cambio proponer un método que considere "como único valor crítico a diferença". (2000 [1978]: 19) Al recoger el potencial desestabilizador de la noción de suplemento derrideano, el brasileño cuestiona conceptos como los de unidad y pureza que caracterizan al pensamiento metropolitano (2000 [1978]: 16). El entre-lugar refiere ante todo a una posición desajustada de marcos culturales jerárquicos preestablecidos, y por ello es útil para describir y reflexionar sobre las circunstancias en que Rodolfo Lenz desarrolló su pensamiento. Dieciséis años más tarde, bebiendo de la misma fuente teórica pero desde una palestra metropolitana, Homi Bhabha (1994: 2 y pss.) acuñaría un concepto similar: espacios "in-between". 


\section{EL VERDADERO FOLCLOR}

Considerando el alta estima de Lenz por las producciones del habla vulgar y el sofisticado método de registro que creó para documentarlas, llama la atención que haya dedicado un estudio tan extenso y profundo a una manifestación escrita, como lo es la poesía popular impresa. Desde las primeras páginas de "Sobre la poesía popular impresa de Santiago de Chile: contribución al folklore chileno" $(1919)^{9}$, Lenz justifica el objeto y su interés (valor histórico - antigüedad, representatividad-y etnológico -forman parte de la vida del pueblo-), destacando sin embargo que estas manifestaciones son espúreas, de baja calidad y que casi no merecen el nombre de poesía ni el epíteto de popular, o sea, folclórica: "el contenido de las hojas que venden los verseros en las calles de Santiago en jeneral está lejos de ser poesía e igualmente lejos de ser popular. Es una literatura de alta alcurnia que ha caído al barro" (1919: 617) ${ }^{10}$. Más adelante, se queja de la técnica de contrapunto de los poetas Hipólito Cordero y Daniel Meneses, quienes "están agotando los tesoros de su indijesta sabiduría tanto como el acervo de injurias i denuestos" (545), comenta sus muchos "absurdos rimados" (547) y remata sentenciando que "esta poesía se está muriendo de su falta de verdad interior" (622). Pues bien, ¿cómo explicamos esta negativa a concederles el nombre de poesía popular? Y luego, ¿qué manifestación criolla considera entonces legítimamente folclórica?

Lenz lamenta que estas publicaciones hayan "perdido casi por completo el rumbo que tenían antes" (513), es decir, que en algún momento sí fueron populares. A continuación, escribe que han sido desplazadas por la oferta de materiales internacionales (la moda de las zarzuelas y las operetas españolas) o sensacionalistas, con lo que la "publicación de hojas de versos ha llegado a ser cuestión mercantil de ciertas imprentas" (1919: 514); por otra parte, señala que la mayor cultura del pueblo "ha disminuído la afición a la antigua poesía popular" (514). Una posibilidad sería considerar que estas no son razones suficientes para negar la autenticidad del material: tanto la menor circulación de "cuadernitos" como la creciente educación del bajo pueblo

9 La primera parte de este estudio fue publicada en un libro de homenaje al profesor Alfred Tobler, en Alemania en 1895, con el título "Ueber die gedruckte Volkspoesie von Santiago de Chile. Ein Beitrag zur chilenischen Volkskunde". En 1919 se publicó íntegro en los Anales de la Universidad de Chile.

10 El único poeta que salva Lenz, ya sobre el final del texto, es Bernardino Guajardo ( $c f$. 1919: 620). 
son factores que solo explican la dimensión externa de las obras, pero poco dirían de su constitución interna o calidad. En cuanto a si son o no poesía, Lenz solo reserva el término a las manifestaciones "sanas" o "naturales" de la lengua vulgar. Solo es literatura vulgar esa que cultiva el pueblo y que emana del mismo pueblo, y la que presenta Lenz no cumpliría con ese requisito, pues se basa en un producto estético de élite que corresponde a una cultura extranjera: es una "dejeneración vulgar de la lírica cortesana de antaño" (543). Así, estas poesías interesan solo en tanto trasplante y adaptación "degenerada"11.

En marzo de 1894, los mismos mes y año en que Lenz tradujo al castellano la primera parte de su "Sobre la poesía popular..." (1919: 513), dio término a un escrito titulado "Die echte Volkspoesie. Dichtung und Musik der Frauen" que se mantuvo inédito hasta su muerte. "La auténtica poesía folklórica. $\mathrm{La}$ expresión poética y musical de las mujeres" -según la traducción de Manuel Dannemann (Cf. Lenz 2003-2004: 85-86)-aborda el arte popular femenino de las cantoras de cuecas y tonadas, y es notoriamente más breve que el estudio dedicado al arte masculino, cuyo título preliminar era "Santiaguiner Poetas populares. Material" 12 . En aquel, Lenz destaca el talante alegre de las canciones femeninas de tono lírico, que opone a la poesía seria y de tono épico-didáctico de los hombres (2003-2004: 89-90). Dannemann conjetura que la voluntad de Lenz habría sido publicar ambos textos bajo el encabezado "La auténtica poesía folclórica [Die echte Volkspoesie]", pero que por razones desconocidas separó ambas ramas poéticas y dio prioridad a la masculina (2003-2004: 86). Aquí nos gustaría proponer otra lectura de este hecho.

A nuestro entender, y de acuerdo con lo presentado más arriba, la separación por géneros obedece a que Lenz consideraba como auténtica tan solo la rama femenina, lo que además ayuda a entender su apreciación desfavorable de la masculina. Este es justamente el sentido del título: "Die echte Volkspoesie". Muchos fragmentos de este texto se encuentran, con

11 Esta manera de entender la poesía chilena vale para todo el continente americano. Así, hablando del gaucho y la gauchesca: "esta lengua del gaucho y del guaso es en su esencia el mismo castellano que se usa en las altas clases de la buena sociedad; es un castellano literario vulgarizado y degenerado; es, en fin, una hija de la lengua literaria, mientras que en Europa el habla del pueblo indocto es la madre de la lengua literaria". (Lenz 1893b: 37-38)

12 Aparte de la traducción y presentación que Dannemann (2003-2004) hace del escrito, el único estudio que conocemos sobre este ensayo es el de Maximiliano Salinas (2011), que realmente es una nueva presentación, pues se refiere a él como un "manuscrito inédito" (siendo que, como hemos dicho, Dannemann ya lo había traducido y publicado nueve años antes) con el interés de rescatar sobre todo la temática amorosa de los cantos cuyas transcripciones Lenz adjuntara al final del artículo (Dannemann 2003-2004: 100). 
escasas modificaciones, también en "Sobre la poesía...". En todos ellos, cuando Lenz se refiere al arte de las cantoras ${ }^{13}$ incluye el adjetivo "echte", que Dannemann traduce como "auténtica" y Lenz como "verdadera" ${ }^{4}$. La comparación pronto se explicita:

En jeneral no cabe la menor duda de que ya solamente el canto femenino con sus poesías livianas (tonadas) i acompañamientos de bailes (cuecas), es verdaderamente popular; el canto masculino lo ha sido en sus oríjenes, pero hoi sobrevive únicamente en pobres restos, que, por esto, son tanto más interesantes para el folklorista. (1919: 522) $)^{15}$

Como bien apunta Dannemann, en este fragmento Lenz se refiere al "proceso de folclorización" (cit. en Lenz 2003-2004: 89) por el que atraviesa el canto femenino, es decir, su inserción en el seno de la vida del pueblo y su distancia respecto de la tecnología de reproducción moderna. En otras palabras, la autenticidad del canto femenino estaría asegurada por el permanente cultivo que ese autor masivo y anónimo llamado "pueblo" hace de él a través de sucesivas transformaciones (2003-2004: 89). Ahora bien, no se debe pensar en una oposición simple entre ambos términos, sino que existen espacios donde se relacionan. Los poetas populares también recogen algunas tonadas y cuecas, pero las imprimen (dato significativo) en lugares marginales: "De vez en cuando se ocupa algún espacio sobrante para imprimir cuecas, tonadas, cantares i otras canciones livianas que pertenecen a la verdadera poesía popular cantada jeneralmente sólo por las cantoras" (1919: 578, énfasis en

13 "La poesía propiamente popular de estrofas cortas, las tonadas en cuartetas i quintillas, los versos de cueca que cantan las mujeres, encierran a veces verdaderas joyas de lindos pensamientos espresados en palabras sencillas, pero sentidas" (1919: 542, énfasis nuestro); "Todas las demas composiciones en cuartetas i quintillas que se hallan ocasionalmente en las hojas de los populares o son poesía literaria destinada a la lectura o recitación, o pertenecen a la poesía propiamente popular que cantan las cantoras con acompañamiento de la guitarra o del arpa, cuecas i tonadas, estas últimas a menudo en forma de glosa" (588, énfasis nuestro).

14 Lenz escribe: "las verdaderas cuecas y tonadas populares sólo rara vez se apuntan i menos se imprimen. Andan por millares de boca en boca, en estrofas aisladas i menos a menudo en composiciones enteras; se varían i se improvisan siempre de nuevo" (1919: 522523). La traducción de Dannemann, en tanto: "Los auténticos bailes y canciones -cuecas y tonadas - de las mujeres se escriben raras veces y, menos aún son impresos. Se difunden por miles mediante algunas de sus estrofas, excepcionalmente con sus textos completos, de boca en boca, y son sin cesar re-elaboradas y combinadas". (2003-2004: 89, énfasis original)

15 En otro texto, el mismo Dannemann (1989-1990: 88-89) rectifica, por cuanto la mirada de Lenz comprende un área de producción muy limitada, y afirma que en otras zonas ha existido una poesía cantada de tipo juglaresca desde mediados de siglo XIX. 
el original). Con todo, la preferencia de Lenz hacia las transcripciones fieles del habla se halla por doquier en estos y otros textos de esos años.

Si el entusiasmo del alemán hacia los impresos de los puetas se explica por su circunstancia (pronta desaparición) y por su modalidad de cultivo, entonces quizás la disputa en torno a lo popular y a los contenidos que corresponden a manifestaciones legítimas del pueblo pueda abrirse acudiendo a la distinción que hace el pensamiento romántico entre Naturpoesie (o Naturdichtung) y Kunstpoesie. Jacob Grimm retoma este binomio herderiano para pensar la "poesía natural", esa que surge por sí sola desde el seno de la comunidad nacional y que por ende expresa fielmente su "espíritu" (Geist) o "alma" (Seele), frente a la "poesía artística" (Kunstpoesie), fruto del trabajo individual (Bauman y Briggs 2003: 203-205). La diferencia se debe al carácter espontáneo e internamente motivado de la primera, en oposición al proceso de elaboración implícito en la segunda. En este sentido, no resulta ocioso recordar que Lenz no anota ninguno de los nombres de las mujeres informantes, quienes permanecen anónimas, pero en cambio sí escribe todos los nombres de los poetas populares. La oposición también es reforzada por el hecho de que solo los impresos se relacionan con temas contingentes - "[s]alen casi sólo con motivo de algún acontecimiento estraordinario, un asesinato atroz, un accidente, un fusilamiento de algún criminal, etc." (1919: 523)-, o sea, están determinados por el ritmo del mundo exterior, el tiempo siempre disponible del calendario (Anderson 1993: 46); los temas de las mujeres, amorosos, en cambio, aunque tampoco originales, "se hallan en la lírica de todas las naciones" (Lenz 1919: 542-543) y entonces escapan a la determinación de factores sociales (Bauman y Briggs 2003: 203).

En su conferencia "Homero y la filología clásica", dictada en 1869 en la Universidad de Basilea, un joven Nietzsche (1951) aún comprometido con la filología se encarga de desmantelar esta contraposición. Como es usual, adelantándose a críticas contemporáneas, Nietzsche la califica de "superstición", pues toda poesía se debe al "alma popular", al "impulso inconsciente del pueblo como el único resorte, como la única palanca de la llamada historia del mundo" (35), pero al mismo tiempo "toda poesía, $\mathrm{y}$, naturalmente también la poesía popular, necesita de un individuo que la transmita" (35). El punto radica en repensar el concepto de lo popular a partir del de tradición: aun cuando puedan encontrarse en tradiciones distintas, tanto el poeta individual como la "masa poeta" se desarrollan a partir de la fuerza de la tradición, de un legado común, y por tanto es popular, ya sea hacia arriba (si es de clase social elevada) o hacia abajo (si es de clase popular).

En el caso de Lenz, el esencialismo - no hay otra palabra- llega aun más lejos, pues niega el aura de "lo auténtico" a una poesía que, incluso habiendo "nacido en el suelo del sentimiento popular" (Nietzsche 1951: 35), 
no lo sería por su origen foráneo y por no hallarse sometida a y determinada por la perpetua (re)creación colectiva ${ }^{16}$. En estrecha relación con esa idea de transformación está la de fidelidad formal al habla "viva": Lenz toma por los mejores poetas a los que componen sus rimas prestando atención a la pronunciación vulgar (1919: 571). En este sentido, el valor fonético que ofrecen los materiales de los puetas y los de las cantoras es distinto: mientras la escritura de los primeros es útil por su distancia y contraste con la pronunciación vulgar, la escritura de las segundas imita a la pronunciación y se acerca al concepto de transcripción fonética ${ }^{17}$. Lenz guarda particular aprecio por este segundo conjunto de materiales:

Yo considero muy útil este hecho. El examen de estos textos escritos por el pueblo, respecto de los cuales se sabe con exactitud qué pronunciación es la que se emplea, nos da puntos de apoyo sobre el grado de confiabilidad de antiguos manuscritos. El texto que aquí se presenta en su original estaba escrito en líneas continuas, no en versos, y en sílabas, no en palabras. $(2003-2004: 93)^{18}$

Según esta visión, lo popular es sancionado únicamente por su cualidad dinámico-inmediata (privilegio de la presencia-voz) en lo formal, y por la tematización de un fondo común, ya sea nacional o transnacional (privilegio de alguno de los géneros propios del folclor), en cuanto a contenido: la autenticidad se reserva a manifestaciones inmediatas en la transmisión, colectivas en la recreación y comunes en la identificación cultural.

De las dos publicaciones comentadas, nos interesa sobre todo el concepto de resto - e.g. " "el canto masculino [...] hoi sobrevive únicamente en pobres restos" (1919: 522)-, pues jugará un papel importante en el proyecto lenziano de refundar la nacionalidad chilena a partir de un archivo que conserve la particularidad criolla. Este archivo nacional, que asimilará dentro de sí a ese otro archivo mapuche ${ }^{19}$, está ya sugerido en los "Ensayos filológicos

16 Bien indica Pavez (2015: 80) que los poetas mapuche con que trabajó Lenz problematizan esta oposición al ser poetas creadores y también populares. Ahora bien, se debe notar que el criterio para evaluar el nivel de autenticidad de la poesía es diferente en cada caso; pareciera que la pertenencia del informante o poeta a la etnia mapuche ya da crédito suficiente de ella, mientras que lo auténticamente chileno debe satisfacer, como lo vimos, bastantes requisitos. En este punto, Lenz parece más rígido que en otras materias, y particularmente romántico.

17 Lenz se extiende largamente al respecto en sus "Ensayos filológicos americanos" (1894: 359-365).

18 Parte de esta misma idea se encuentra en Lenz 1919: 572.

19 La idea de asimilación del otro es constante en Lenz (1894: 131-132; 1895-1897: XIII-XV; 1919: 517-519): tal como en su hipótesis sustratista del español de Chile, la 


\section{americanos", un tercer texto publicado en 1894 en el que Lenz comprende} el folclor como rama de una filología que toma su modelo de las ciencias naturales. Luego de referir la metáfora botánica de Schleicher ${ }^{20}$ según la cual la lengua que interesa al científico es como la planta que crece en la intemperie, cita un discurso pronunciado en 1884 por la escritora Emilia Pardo Bazán, presidenta de la Sociedad de Folklore Gallego. La escritora denuncia el proceso de depredación que sufre la tradición popular a costa de la máquina civilizatoria y, a continuación, llama al rescate de todos los documentos que puedan dar cuenta de aquella:

el Foklore quiere recoger esas tradiciones que se pierden, esas costumbres que se olvidan i esos vestijios de remotas edades que corren el riesgo de desaparecer para siempre. Quiere recojerlos, no con el fin de poner otra vez en uso lo que cayó en desuso, [...] sino con el de archivarlos,

particularidad etnológica del pueblo chileno está dada por la "sana" (eugenésica) integración del elemento mapuche en el cuerpo nacional chileno. Las empresas folclóricas de esta época necesitan que los elementos a archivar estén extintos o bien en vías de estarlo, pues la misma idea de un archivo-museo supone la estabilidad hermenéutica de sus materiales y, por tanto, su tratamiento en tanto objetos. Si la cultura está plenamente viva, la archivación no puede tener lugar (como acabamos de ver con el ejemplo de "Die echte Volkspoesie..."). Por tanto, la cultura mapuche solo puede mantenerse viva a partir de la integración de sus restos o fragmentos en la chilena. Entre ejemplos que abundan, es elocuente una entrevista (Anatole 1917: 4) en que Lenz recomienda a los jóvenes chilenos practicar el deporte de la chueca, pues con ello estarían haciendo un bien a la patria; como parte de la misma operación, opina que "hai muchas palabras araucanas que podrían incorporarse a la terminolojía deportiva. Sería un bello jesto de nacionalismo" (cit. en Anatole 1917: 4). Esto es justamente lo que hace en su Diccionario etimológico de voces chilenas derivadas de lenguas indígenas americanas (19051910), sacar las consecuencias del impacto que ciertas palabras de origen indígena tiene en la conformación cultural de la nación; de hecho, presenta su diccionario como una "contribución a ese futuro [...] diccionario nacional chileno" (22); allí Lenz compara la lengua chilena con un cuerpo marcado por cicatrices (palabras) como resultado de la lucha interétnica (42). De ahí que no compartamos conjeturas como las de Pavez, quien, destacando la exclamación que Lenz incluye en una carta dirigida a Moesbach, al terminar la traducción de las memorias de Pascual Coña -“Aflayai mapuche dungu!” (cit. en Pavez 2015: 70)-, afirma: "Quizás Lenz quería íntimamente la conservación de la lengua, pero eso era algo que no podía decir en los medios chilenos, donde esta se consideraba un obstáculo a la chilenización" (70). La entrevista citada prueba que Lenz no censuraba en público sus ideas al respecto; por otra parte, no debe confundirse la viva rehabilitación de un idioma (sugerida en la conjetura) con su conservación museográfica (esto es, yerta), previa integración.

20 Se debe decir que ya Lenz se distancia de Schleicher en el sentido de que piensa la lengua-como ya lo hiciera Wilhelm von Humboldt-como un organismo, pero no le depara la decadencia ( $c f$. Formigari 2004: 142), sino que ve en ella posibilidades fecundadoras siempre renovadas a partir de la mezcla eugenésica de razas que se daría en Chile (1894: 131; 1919: 518-519). Esta aptitud del castellano de Chile para formar una nueva lengua aparece además en su ensayo "Nacionalidad y lenguaje" (Lenz 1893b: 39). 
evitar su total desaparicion, conservar su memoria i formar con ellos, por decirlo así, un museo universal donde puedan estudiar los doctos la historia completa del pasado. (Pardo Bazán, cit. en Lenz 1894: 357)

Nuevamente se convocan los vestigios o restos del pasado, reunidos ahora en un ambiente separado de su hábitat natural para el estudio de los eruditos; tal es la ideología museográfica que aspira a la objetivación de formas "en escaso uso", no con fines de rehabilitación en la comunidad, sino tan solo para conservarlas. Este diferente rendimiento científico del patrimonio "vivo" respecto del "muerto", llevado por una idea de autenticidad algo estrecha, podría explicar por qué Lenz no publicó "Die echte Volkspoesie" y por qué resultó tan magro en comparación con "Sobre la poesía popular impresa...".

Quince años después, cuando funda la Sociedad de Folklore Chileno" Lenz considera el folclor como rama no de la filología, sino de la etnología, encargada de estudiar "las leyes de la formación de la humanidad con el objeto de presentar un cuadro de su vida psíquica" (1909: 5), según la formulación de Adolf Bastian. La etnología sería "el punto culminante de todas las ciencias" (5) al aprovechar los hallazgos de las demás para alcanzar su objetivo: estudiar "lo que piensan los pueblos como colectividad" (5). En virtud de este relativo desplazamiento disciplinar, con el Programa de la Sociedad de Folklore Chileno se observa un viraje más decidido hacia la psicología étnica de Wilhelm Wundt ${ }^{22}$, así como hacia los postulados de Raimund Kaindl, en Die Volkskunde. Ihre Bedeutung, ihre Ziele und ihre Methode [El folklore, su importancia, sus fines y su método] (1903), lo que repercutirá en una nueva concepción de los restos. Además de enfatizar el carácter nacionalista de la tarea folclórica -"Hai que estudiar el saber popular de todas las razas i de todos los restos de pueblos en América; pero ante todo lo propiamente criollo" (1909: 11)-, Lenz señala que su texto

21 La Sociedad de Folklore Chileno fue la primera institución de su tipo en América Latina, y gozó del reconocimiento de la intelectualidad nacional, a pesar de los ataques referidos en la nota a pie 20. Sus cofundadores fueron: Enrique Blanchard-Chessi, Agustín Cannobio, Eliodoro Flores, Maximiano Flores, Ricardo Latcham, Ramón Laval, Antonio Orrego Barros, Julio Vicuña Cifuentes y Francisco Zapata Lillo. La institución pasó a formar parte de la Sociedad Chilena de Historia y Geografía en 1913, con el nombre de Sección Folklore (Dannemann 2010: 58; Dannemann 1989-1990: 82).

22 Ferreccio (1979) señala que en los Estudios araucanos (1895-1897), Lenz toma por guía el trabajo de Georg von der Gabelentz, pero que en La oración y sus partes (1916) se rige por la teoría de Wundt (9). El Programa de la Sociedad de Folklore Chileno es de 1909, lo que da cuenta de que Lenz lo había leido antes, y de ahí en más lo citará prácticamente en todos sus escritos. 
es, "en lo esencial, un estracto" (1909: 5) del de Kaindl23. Volviendo sobre ideas habituales, el alemán refiere el afán museificador y totalizador que persiguen los estudios folclóricos: además de "formar museos" con los "preciosos restos" del alma popular, se debe intentar construir una imagen lo más completa posible de la tradición.

Ahora bien, es elocuente que Lenz reproduzca al final de su texto los últimos párrafos del capítulo 1 del de Kaindl. Allí, Kaindl se refiere a la existencia de vacíos en lo que llama el "sublime edificio": "En su debido lugar, [cualquier piedra] puede rellenar un vacío en el sublime edificio, puede ser una piedra útil para la construcción"; y más adelante: "Para obtener el fundamento en que se levantará la filosofía del porvenir, hai que recojer todas las manifestaciones de la idea étnica, hai que recojerlas sin dejar vacíos" (cit. en Lenz 1909: 11). Comprendemos que aquellos vacíos no son, pues, algo dado de antemano, algo que exista antes de la labor de archivación, sino que son producidos en virtud de la archivación misma; es decir, es justamente la producción del vacío, de la pérdida y de los "preciosos restos" la que permite a la ciencia folclórica fundarse a sí misma ${ }^{24}$. La dinámica circular, interdependiente, entre resto y vacío constituye la economía del archivo y su condición de posibilidad.

La expresión "sublime edificio", que de alguna manera funciona como hiperónimo de otros como museo y archivo, aporta un cariz constructivo y vivo a términos que hemos ubicado dentro del campo semántico de la muerte. El término "edificio" (Gebäude), además, se asocia estrechamente con las discusiones propias de la filología de la época sobre tipos de lengua. Heymann Steinthal ${ }^{25}$ (1855: 128-130) anota que Wilhelm von Humboldt, cuya figura se proyecta durante todo el período, utiliza frecuentemente organische Sprachgebäude ("edificio orgánico de la lengua") y organischer Sprachbau ("estructura orgánica de la lengua" o simplemente "organismo de la lengua"), mientras que el propio Lenz habla del "edificio gramatical" obtenido "por abstracciones de la lengua viva" (1893a: 246), o sea, el Sprachbau. Estos términos, sin embargo, no se refieren al pensamiento

23 Tan es así que la primera línea del escrito es traducción literal de la primera de Kaindl: "El Folklore es una rama de la etnolojía" ["Die Volkskunde (Folklore) ist ein Zweig der Völkerwissenschaft (Ethnologie)" (1)].

24 Esto es lo que quiere decir Derrida al afirmar que "la estructura técnica del archivo archivante determina asimismo la estructura del contenido archivable en su surgir mismo y en su relación con el porvenir. La archivación produce, tanto como registra, el acontecimiento". (1997: 24)

25 Lenz lo cita en el extracto de Kaindl y luego en La enseñanza del castellano y la reforma de la gramática (1920a) y en La oración y sus partes (1920b). 
articulado o a la reserva de palabras, sino al "lenguaje en sí" (die Sprache an sich), a una fuerza espiritual que atravesaría esos elementos materiales y que, por tanto, tampoco corresponde del todo a la lógica o a la gramática de una lengua. Con todo, de acuerdo con la idea de energeia, según la cual el lenguaje es ante todo una actividad productiva, Humboldt daba especial importancia al estudio del habla para derivar de allí un Nationalcharakter ${ }^{26}$.

Steinthal, a quien Wundt (1900: 17) reconoce junto con Lazarus el mérito de haber acuñado el término Völkerpsychologie, retoma entonces el concepto de Sprachgebäude y lo reinterpreta en el marco del habla y de su propuesta sobre el paralelismo psicofísico que rige la conducta humana a nivel colectivo. Los mecanismos guía de la vida mental (seelisches Leben), ya descritos por Steinthal en términos de una correlación entre sonidos y representaciones, son compartidos también por Wundt (Formigari 2004: 156-157). La asociación entre lo físico y lo psicológico determina la relación entre pensamientos, conceptos y juicios, pues el individuo puede arribar a una representación total justamente a partir de los rastros fónicos conscientes o inconscientes que han quedado como restos en su psique producto de previas representaciones. Este tipo de uniones aperceptivas son explicadas por Lenz en La oración y sus partes:

Depende de nuestras experiencias que el resultado de esa síntesis [aperceptiva] sea más o menos razonable. Mientras mayor sea el número de asociaciones que podamos formar con los "rastros", las "disposiciones" dejadas por otras experiencias, mejor servirán las representaciones totales para formar conceptos y juicios sobre esta base. (1920b: 26)

Aquel extracto de Lenz sigue la misma lógica del de Steinthal:

Así, por medio del habla, se forma en la mente $[\text { Seele }]^{27}$ un "montón de escombros" [Schutte], de acuerdo con la ingeniosa expresión de Herbart,

26 "Justamente lo más elevado y sutil [...] sólo en el hablar trabado se lo puede percibir o intuir (lo que prueba nuevamente que el lenguaje propiamente dicho está en el acto real de producirlo). Toda investigación que aspire a penetrar la esencia viva del lenguaje deberá tomar ese hablar trabado por lo primero y verdadero. Su dislocación en palabras y reglas no es más que el torpe producto inerte de la descomposición científica". (Humboldt 65)

27 Traducimos aquí Seele por "mente" porque su contexto de uso es positivista; en cambio, antes hemos escrito "alma" por tomarse de una formulación de los hermanos Grimm, o sea, de un contexto romántico en que el término adquiere un cariz metafísico o religioso. Estos aspectos no tienen cabida para la psicología empirista de la época; de hecho, como afirma el mismo Wundt más tarde, Seele "no puede tener otro significado que la efectiva relación dada entre las vivencias psíquicas". (1900: 9, traducción nuestra) 
material fónico que alguna vez formó un edificio [Gebäude] de juicios mutuamente conectados; con el tiempo, el edificio se ha desmoronado y solo quedan piedras y vigas tiradas sin conexión ni orden entre sí, pero cada pieza lleva las huellas [Spuren] de su conexión previa. / Ahora, sin embargo, la misma piedra muestra diversas conexiones, y el mismo tipo de combinación se delata en diferentes piedras y vigas. [...] Al hablar, la mente vuelve siempre sobre estos escombros y usa el material según las junturas encontradas. (Steinthal 1855: 347, traducción nuestra)

Estos dos tipos de restos circulan por diferentes campos: uno en el edificio del pasado cultural y otro en el edificio del presente de la lengua; los restos que el erudito debe salvar para exponer como piezas muertas del pasado y los restos de cuya infinita combinatoria depende el régimen productivo de la imaginación popular. ¿Hasta qué punto esta oposición es sostenible? Como escribe Ortiz (2017), el resto que entra muerto al archivo adquiere allí una nueva vitalidad dada por el fetichismo con que se anula su valor de uso y se lo integra en una nueva economía alienada. Tal oposición, que se espeja en la anterior (Naturpoesie/Kunstpoesie), entrará en crisis cuando Lenz comience a relacionar de manera más decidida los frutos de sus labores investigativas y pedagógicas.

\section{EL FOLCLOR EN LA ESCUELA: CONSTRUIR LA LENGUA NACIONAL}

Si la operación wundtiana de descomponer una representación total en representaciones parciales sirve a Lenz para el análisis lógico y gramatical en La oración y sus partes, también le sirve para evaluar relatos: el folclor sería un conjunto de representaciones totales e indiferenciadas cuya descomposición, análisis y comparación narratológica evidenciaría las economías psíquicas que diferencian a una comunidad nacional de otra. No es otra cosa lo que está detrás del proyecto de "Un grupo de consejas chilenas" (1911). Aun cuando Lenz ya había comparado narraciones en sus Estudios araucanos, es a propósito de las consejas (Märchen, cuentos de hadas) que la técnica comparatista pasa al primer plano, comenzando por un deslinde entre tipos de narración popular y su valor para la determinación de una mente colectiva. El objetivo de Lenz, que ahora es aportar a la comprensión de la auténtica "alma nacional", es decir, a la descripción de una matriz psicológica chilena, pasa necesariamente por descubrir el modo de apropiación del relato universal. 
El modelo de recolección de textos ensayado en "Die echte Volkspoesie" y estrenado en sus Estudios araucanos, sobre la base de "las fuentes vivas del idioma hablado" (Lenz 1895-1897: XX), se afinará en "Un grupo de consejas chilenas". Lenz critica allí las primeras empresas de novelística comparada, entre ellas, la de los hermanos Grimm, por la premisa monogenética de los cuentos populares. Considera estos relatos como parte constitutiva del acervo común de la cultura popular mundial y como una especie de tabula rasa, pues su contenido es premoral y su referencialidad indeterminada (Lenz 1912: 17-18). Así, no habría razón para relegarlos a un estadio menos evolucionado de cultura (9); incluso cita a Franz Boas para enfatizar el punto: "hasta hoi no hai ninguna prueba científica de que la raza blanca sea de suyo superior a alguna de las demas" (Lenz 1912: 10). De ello se deriva, entre otras cosas, su potencial rendimiento como material de un estudio etnológico integral (que él solo proyecta), pues se supone a cada comunidad nacional una cierta manera de adaptar y modificar el material, de imprimir su marca en él. Gracias a su estudio temático, sin embargo, afirma distinguir "un perfume suave, pero perceptible del alma chilena" (148), "rica fuente de sana poesía" (148). ¿Cómo alcanza a respirar Lenz este aroma-que deberíamos calificar, más bien, como embriagador, a juzgar por la pasión de la postrera arenga nacionalista ( $c f$. Lenz 1912: 150)-, si deja pendiente el estudio psicológico de los argumentos? Desde nuestra perspectiva, aun cuando Lenz no alcanza a ver el "edificio" completo, sí repara en los restos y adivina sus huellas, entendiéndolas como índices de una construcción en continuo movimiento.

En este sentido, Lenz retoma el concepto de imaginación popular, que comandaría las relaciones entre los restos. Declara que uno de los problemas más importantes para el folclor es seguir "el libre juego de la imajinacion popular" (1912: 20), estimulada cuando un narrador del pueblo olvida una parte del relato: "Creo que puede considerarse netamente como característico del trabajo de la imajinacion popular que ella completa por combinaciones con otros recuerdos los rasgos olvidados, pero que no inventa facilmente algo enteramente nuevo" (19-20). Retomando la economía de los restos vivos, dichas invenciones (Erfindung) o creaciones (Schöpfung) se dan por los múltiples agregados, desagregados, transformaciones y reemplazos que sufren ciertas representaciones ${ }^{28}$. Las consejas son, pues, un conjunto de

28 No es otro es el desafío que Wundt formula para la disciplina en la segunda edición de su Völkerpsychologie: "dado que cada comunidad, aunque no añade nuevos elementos síquicos a los contenidos de la conciencia de sus miembros, produce ella misma nuevas creaciones espirituales [geistige Schöpfung] con las condiciones de conexión y de interacción, así la psicología étnica tiene en aquellas y en la demostración de sus relaciones con las fuerzas 
casos a partir de los que luego podrían levantarse regularidades generativas, combinatorias y relacionales ${ }^{29}$.

Extraemos de lo anterior que "Un grupo de consejas chilenas" es la obra cumbre de Lenz en el estudio del folclor chileno tanto por la riqueza de los materiales ofrecidos como por la precisión y sofisticación analíticas desplegadas. En esta línea, si quince años antes (Lenz 1919: 522-523, 576578; 2003-2004: 89, 98) ha notado que los cantores, cantoras y payadores son apreciados por el pueblo debido a su capacidad de improvisación sobre la base de estrofas sueltas, es recién ahora, después de haber perfeccionado un método de recolección y de haber adoptado un modelo teórico integral como el de Wundt, que los materiales del habla muestran todo su rendimiento y alcance. En esta obra, Lenz parece encontrar un lugar intermedio entre el folclorista resignado a la observación distante de lo auténticamente folclórico y el arqueólogo que enmarca los moribundos restos en el museo; sin llegar aún a describir o reducir la lógica viva del pensamiento, ya intuye su funcionamiento. El autor no disimula su satisfacción hacia tamaño avance en la averiguación del "alma nacional" y se encarga de traducir el valor científico del estudio en un valor cultural. La estrategia, común en él -y cuyo principal índice se delate acaso en su firme inclinación a escribir "alma" y jamás "mente" nacional (véase la nota a pie 28)-, es realizada aquí de manera explícita y directa, fluidez que ilustra la resignificación política que sufren los productos de su investigación, de acuerdo con su voluntad de aportar no solo a la ciencia sino también a la transformación de las bases simbólicoafectivas de la comunidad chilena. De ahí que releve la imaginación como facultad mental superior incluso a la lógica:

La imajinacion no es una aberracion del raciocinio lójico, sino una facultad primordial del alma humana; no es tan solo la madre de las artes sino también de las ciencias. El hombre de jenio se distingue del individuo vulgar mucho mas por la superioridad de su imajinacion que por la mayor fuerza lójica del intelecto. [...] No solo la enseñanza de artes, como el dibujo, se ha resentido hasta estos últimos tiempos por la falta de cultivo de la imajinacion sino que lo mismo ha sido el caso con respecto a la enseñanza del idioma patrio. / El cultivo del don de la palabra

síquicas ya activas en la consciencia individual su gran tarea independiente". (1904: 18, traducción nuestra)

29 Aunque Lenz ya habla de la imaginación popular y de la inteligencia creadora en sus Estudios araucanos (1895-1897: 177-178, 327, 329,359), no se encuentra allí una descripción del libre juego de la imaginación sobre la base de los restos y vacíos narrativos. 
es en primer lugar también un arte, que depende de la imajinacion mas que de ninguna otra facultad síquica. (Lenz 1912: 18-19)

Hay varios puntos interesantes en este párrafo. Además de la oscilación retórica entre los sinónimos "facultad del alma" y "facultad síquica" para la imaginación ${ }^{30}$, la idea de "genio" ya no depende de un rapto espontáneo sino de la capacidad generativa y relacional de la mente. Ya no se trata de la oposición romántica entre Naturpoesie/Kunstpoesie, insostenible aquí incluso desde las condiciones de producción de los materiales con que trabaja Lenz, producidos por personas alfabetizadas de "mediana cultura" (no popular y/o rural): todos los relatos, con excepción de uno, han sido escritos por estudiantes de liceos o escuelas superiores o inferiores pertenecientes al "medio pelo" (27-31). Todo ello -y esto es lo más importante- se da en un párrafo que pasa de la reflexión antropológica a la pedagógica en un continuo, gracias a ese interés común que es el cultivo de las formas folclóricas. En sintonía con la idea de autenticidad, la estrategia pedagógica que Lenz defiende para la enseñanza del idioma patrio es la de la producción versus la previa reproducción; es en vistas de esta "libre producción literaria del niño" (19) que se recomienda las consejas como tema de las composiciones escritas: "Lo aconsejamos, pues a los profesores de castellano para procurar a la vez al niño un buen ejercicio i al folklore interesantes materiales" (19). El tránsito es claro: originado en el campo o en las clases urbanas baja o media baja, el folclor llega luego a la escuela y desde allí pasa al escritorio del filólogo.

La idea de lo auténticamente popular se flexibiliza: si en el Programa... su único recipiente era la memoria de quienes no han sido alfabetizados ${ }^{31}$, ahora ingresa a la escuela con lápiz en mano. Este tránsito de la oralidad a la escritura evidencia que el objeto mismo del folclor es conceptualizado de otro modo por Lenz (y, como lo sugiere nuestro epígrafe, de ahí en más no resistió el atractivo de la metáfora escrituraria para explicar el funcionamiento del habla). Además, el cambio destacaría algunas diferencias entre los procedimientos de Lenz y de los hermanos Grimm: mientras, como hoy sabemos, los Grimm solían editar los Märchen -muchos de ellos eran

\footnotetext{
30 Más adelante hablará de "la psicolojía del alma nacional" (1918: 222), hermanando ambas acepciones.

31 "Lo esencial es que todos los documentos sean verdaderamente populares; pueden considerarse como tales todos los que viven de la memoria de la jente que no sabe leer i escribir, o al ménos, no maneja libros" (Lenz 1909: 13). Este extracto lo saca Lenz de su anterior "Ensayo de programa para estudios de folklore chileno" (1905) presentado a la Facultad de Humanidades de la Universidad de Chile.
} 
fragmentos que se unían para crear una nueva unidad o bien a los cuales se les insertaban proverbios, volviéndolos un género mixto (Bauman y Briggs 210)-, Lenz, en cambio, guiado por las máximas positivistas de objetividad y fidelidad, no censura composiciones por su contenido (e.g., las de contenido sexual que escandalizaron a ciertos intelectuales de la época) ni tampoco las interviene de manera directa, sino que espera pacientemente que la imaginación popular haga su trabajo y el mismo hablante complete las lagunas del relato, que escuche sus restos para componer un nuevo edificio. Sin embargo, ¿Lenz realmente se mantiene tan objetivo y distante como él piensa? ¿No es acaso la intervención directa solo una de las estrategias de que dispone el filólogo para incidir en sus materiales?

En este sentido, el ingreso (o, mejor, la producción) del folclor en el aula plantea no pocos problemas: la escuela puede ser un espacio idóneo para la cosecha del folclor, pero al mismo tiempo debe ser donde se modela la lengua con grados variables de normatividad ${ }^{32}$. ¿Cómo responder, de nuevo, a esta doble interpelación ideológica: la de la ciencia y la del Estado? Nuestra sospecha es que Lenz tiende a ver los productos de sus labores científicas y pedagógicas como complementarios, y que muchas veces los primeros se supeditan a un objetivo de planificación lingüística que se espera de su agencia estatal. Sin embargo, esta relación nunca está exenta de fricción y no siempre conduce a una síntesis feliz. ¿Podemos afirmar que Lenz trata de igual forma la lengua vulgar en su producción folclórica que en el aula o bien la disección de la primera es tan necesaria como la corrección de la segunda? La curiosa actitud correctiva que adopta al comentar la escritura original de los cuentos es ya un indicio de respuesta: "la mayor parte de las faltas son de aquellas que hacen rabiar a los profesores [...] Acentos i

\footnotetext{
32 Como es sabido, norma no es sinónimo de prescripción. A diferencia de esta última, que suele jerarquizar las variedades de lengua según una asignación de prestigio sustentada en juicios de valor, el concepto de norma está detrás de cada regularidad lingüística observable en los hablantes, es decir, deriva inevitablemente de la práctica lingüística misma, le es inherente (Cameron 1995: 1-6). De hecho, cuando Lenz se pregunta qué es castellano está justamente desplazando la discusión desde la prescripción (prestigio) a la descripción (norma), pues entiende que esa es la cuestión de fondo. Como indica Chávez Fajardo (2011: 96- 98), la pregunta por la definición le permite alejarse del prescriptivismo, abrir un acercamiento sociolinguístico y así entender la estandarización lingüística de una nueva manera enfocada en el uso. El problema entonces no es el concepto de norma sino el tipo de norma y los procesos y mecanismos que concurren en su legitimación desde la perspectiva de sus hablantes. Opuesto al hispanismo monocéntrico y purista, el de Lenz destaca como "uno de los primeros casos de hispanización pluricéntrica, donde en cada variedad se fija y se constituye una norma" (Chávez Fajardo 2011: 97). Por su parte, Soto (2016: 221-226) ha recordado el permanente énfasis de Lenz en la importancia de enseñar la lengua literaria en la escuela.
} 
puntuacion son raros i siempre inciertos; la separacion de las palabras es mui a menudo incorrecta" (1912: 28).

La comparación de algunos pasajes de su obra deja ver cierta similitud entre el tratamiento de la lengua vulgar en el aula y el examen de los textos folclóricos. En su texto sobre la poesía popular impresa, Lenz no comprende la fascinación del pueblo por los versos de los poetas, cargados de "palabrería pseudocientífica", "retumbancia vana" (1919: 545) y "«ripios» excesivos" (1919: 547); y dice de los cultores que "la hinchazón es el casi único mérito de sus producciones" (1919: 618). Más adelante, en Estudios araucanos celebra la precisión estilística de Calvún y la contrasta con la tradición folclórica peninsular: "Especialmente los cuentos españoles pecan por una verbosidad que les roba mucho de la injenuidad inmediata que debe poseer todo cuento popular" (1895-1897: 329). Desde el lado de la pedagogía, en tanto, afirmará que: "Merece la preferencia en la escuela la lengua realmente viva i nó la pronunciacion forzada de la retórica que jeneralmente se enseña" (1893a: 251). Con el tiempo, profundizará su crítica al preceptismo y a los diletantes: en la Memoria sobre las tendencias de la enseñanza del idioma patrio en Chile (1899) censura la "abstracción científica" y la "falsa apreciacion de las bellezas del lenguaje literario i del valor objetivo de los autores de épocas lejanas" (1899a: 15) que gobiernan la enseñanza del idioma. Frente a todo ello, Lenz sostiene que el deber de la instrucción secundaria es "no pervertir el carácter de suyo sobrio del pueblo chileno" (13, énfasis original), enseñar a "observar con criterio sano [...] i expresarse con sencillez natural; el objeto no es criar literatos españoles, sino educar ciudadanos chilenos que respeten su lengua i amen a su pueblo" (1899a: 21-22) $)^{33}$.

De alguna manera, tanto el bajo pueblo como la clase alta adolecerían del mismo mal, ese que habría arruinado la poesía popular y en que los preceptistas, producto de su arribismo extranjerizante, caen: un aspiracionismo cultural que embelesa al pueblo y alaba caricaturas del saber; y que ejercita una élite ignorante que toma la norma peninsular por la única buena. La falta sería la sobreelaboración formal de los materiales, el descalce entre estilo y contenido, que alejaría al folclor de la ingenuidad popular y

33 En carta a Rufino José Cuervo del 28 de julio de 1901, Lenz le solicita recomendación para la cátedra de castellano del Instituto Pedagógico. Sobre las cualidades requeridas, precisa: "Tampoco estos paises nuevos necesitan profesor de retórica, sino personas sobrias que enseñan a decir mucho con pocas palabras y no lo contrario" (cit. en Schütz 1976: 550). Con esta carta le adjunta la Memoria sobre las tendencias..., que presenta como "un grito de combate con motivo de la última reforma de instrucción secundaria, en que estamos empeñados todavía" (551). Véase también Lenz 1899a: 15; 1899b: 4, 24. 
a los estudiantes de la llaneza lógica; que los apartaría, en una palabra, de la verdad o autenticidad expresiva: "De la claridad de la disposicion i de la verdad de las ideas depende el real valor de una composicion mucho mas que de la riqueza i variedad de figuras poéticas i de la abundancia de palabras" (1899b: 51).

En este punto, la sobriedad y mesura que, según Lenz, caracterizan a la expresión nacional y a los materiales folclóricos, se convierten en una exigencia a esa misma expresión. Aquí la máxima científica de la objetividad de Lenz choca con la ideología de la autenticidad (Echtheit) que inauguraran los hermanos Grimm y que de Certeau describe como lugar común de los estudios folclóricos: "La «sobriedad», la versión corta, el vigor: todos estos rasgos, provistos por una genialidad fundamental, permiten decir dónde se encuentra lo «primitivo»" (2004: 58, énfasis en el original). A pesar de esta importante diferencia, que entre otras cosas distingue al romanticismo del positivismo, Lenz esencializa esas mismas características que los cuentos de los Grimm no presentaban de suyo, pues respondían a un proceso editorial, y las levanta como garantía de autenticidad ya no solo del folclor (cosa que ya hizo en 1894) sino también de la expresión chilena toda. Si los Grimm intervienen de manera directa la materia textual, es decir, la cosen, en 1911 Lenz se arroga la autoridad para sancionar una autenticidad ya del todo objetivizada y a priori, pero cuyo único intérprete posible es el filólogo, que ahora trabaja solo con el bisturí para descomponerla y mostrar dónde están las costuras criollas. Con todo, debemos preguntar nuevamente: ¿cuál es la razón de esa absoluta seguridad acerca del carácter genuino de sus materiales?

Lenz puede sancionar la autenticidad de una pieza solo porque antes se aseguró de que cumpliera con los requisitos de "claridad", "verdad" y estilo que -iestos sí!- demandan la corrección del pedagogo. En última instancia, Lenz también interviene pero no sobre un producto, sino sobre el proceso de expresión del niño, modelándolo: "Reprímase sobre todo en las composiciones escritas de los alumnos con toda enerjía el menor indicio de afectación e hinchazón; el lenguaje de los jóvenes educandos debe ser natural i sencillo" (Lenz 1899b: 36). La escuela se convierte al mismo tiempo en el lugar de producción y de modelación del folclor, cuya técnica particularmente incisiva se inscribe en la historia de la dialéctica productiva de lo popular. Si el folclor es el resultado de una dialéctica entre la baja y la alta cultura, por medio de la cual la primera reelabora y luego devuelve al pueblo lo que este le ofreció como materia prima (Ennis 2016: 138-140), la técnica pedagógica de Lenz instala la cultura letrada en el "origen" mismo del folclor para modelarlo. Mientras el tratamiento editorial de los Grimm aún supone un espacio entre ambas culturas (intervención a posteriori sobre 
un producto "original"), la técnica de Lenz amenaza con adelgazar al mínimo esa distancia. Entonces, el folclor se trasplanta: la distancia entre el trabajo de la imaginación popular y el trabajo de la reelaboración letrada es casi anulada y reemplazada por un espacio de fronteras borrosas (la escuela) en que se asiste a la lenta y controlada incubación de la seña nacional popular. En "Un grupo de consejas chilenas" Lenz aún cree estar operando bajo el modelo clásico (producir libros de relatos folclóricos que ayuden a la educación nacional ${ }^{34}$, pero sin duda es la entrada del folclor escrito - no ya la expresión en general- en la escuela el hecho más importante que marca este ensayo ${ }^{35}$.

\title{
4. ESTILO Y LENGUA NACIONAL: DE LA AUTENTICIDAD A LA LEGITIMIDAD
}

\begin{abstract}
"Un grupo de consejas..." se halla a medio camino entre los dos trabajos que, como notó Poblete (2003), permiten trazar el arco pedagógico de Lenz en cuanto al castellano: el Proyecto de programa de castellano (1899) y La composición escolar en lengua patria (1924, pero escrita en 1919). En el primero, el folclor ocupa un lugar secundario, aun cuando Lenz reivindica el valor de la cueca ${ }^{36}$; en el segundo, en cambio, pasará a integrar el repertorio de temas para que los niños preparen composiciones escritas. Inspirado en los trabajos pedagógicos de Wilhelm Lamzsus y Adolf Jensen, que leyera en 1911 y 1912 (es decir, en paralelo a la escritura de "Un grupo..."), Lenz reclama que los temas de las composiciones deben ser cercanos al niño, tales como experiencias suyas o bien relatos de su cultura. Así, recomienda la ilustración de cuentos de hadas, la dramatización de cuentos populares
\end{abstract}

34 "Las colecciones de cuentos populares, de cantos, de juegos, de adivinanzas, que está preparando la Sociedad de Folklore Chileno, en ediciones populares que seguirán a las científicas destinadas sólo a los folkloristas, serán libros de incalculable valor para la educacion nacional". (Lenz 1912: 150)

35 En su excelente estudio sobre la modernización de los métodos de enseñanza de lenguas introducidos por Lenz en la educación primaria y secundaria, Juan Poblete (2003: 258) considera el cuaderno de composición escolar escrita como método que asegura un control mayor sobre el educando, al funcionar como soporte material externo donde la subjetividad del alumno se manifiesta y, por tanto, deviene estudiable y disciplinable.

36 "[S]erá útil recurrir a la poesía popular chilena que los niños conocen para esplicar lo que es una cuarteta, una quintilla, el cambio de versos de siete i cinco sílabas, la seguidilla $\mathrm{i}$ la cueca chilena”. (1899b: 31) 
(1924: 20-21) y, por último, la composición misma en base a imitaciones e invenciones del género:

Composiciones fundadas en la fantasía como antes. Se inventan nuevos casos de brujos, de Pedro Urdemales. Composiciones de historia natural. Cuentos y fábulas de animales. Animales y plantas cuentan su propia vida, tratando de pintar su carácter distinto (El gallo orgulloso, La laucha tímida, El gato astuto, El perro guardián). Cuentos para hacer miedo o reir. (La calchona, El entierro o tesoro escondido). Ampliación de cuentos populares dando con el tono especial de cada personaje (Nuevos cuentos del soldadillo). (1924: 22)

Otra diferencia importante entre ambos trabajos es el grado y tipo de corrección que aplica el profesor: la represión del estilo "afectado" que recomienda a fin de siglo es luego reemplazada por la crítica entre pares. La razón es que, como las composiciones versan ahora sobre temas que interesan a los niños, su respuesta natural a la narracción será la mejor jueza para dirimir asuntos de estilo: "La clase nueva de composición es una Academia cuyas contribuciones todas son voluntarias y la crítica mutua de los alumnos guiados por su maestro enseña a enmendar los defectos de observación que casi siempre son la razón de los defectos del estilo" (19). El pedagogo puede entonces moderar sus intervenciones -el único comentario al respecto se refiere a las exigencias formales: "al principio se tratan con suavidad para no quitar el ánimo, sobre todo a los débiles" (16)- y más bien guiar a los alumnos, cuya naturaleza expresiva demandará de por sí un cierto estilo. Así se resuelve la contradicción entre el "buen estilo" y el aprendizaje por inducción.

La sintonía entre estas ideas y las de "Un grupo de consejas chilenas" es patente. En la escuela, el profesor garantiza un espacio para la reproducción vigilada y modelada de la imaginación popular, imaginación que se dibuja a sí misma con el lápiz en una operación democratizadora (alfabetización universal). La entrada de cada nueva generación en el aula convierte a este espacio en una fuente inagotable de folclor. Sin embargo, ese dibujarse a sí misma necesariamente irá cambiando, sobre todo cuando su autenticidad pasa de ser premisa a meta de sí misma, en un desdoblamiento que sugiere el aforismo nietzcheano de nuestro epígrafe: la cultura popular como noúmeno es el tribunal de la cultura popular como fenómeno. Esto se debe a que el mismo pueblo tiende a la "hinchazón retórica" por el consumo de productos extranjeros, en el caso del folclor, y debido a los resabios de la enseñanza gramatical abstracta y basada en el oropel literario, en el caso de la educación. Entonces, el camino es claro: hay que corregir al pueblo para que, en su expresión, sea fiel a sí mismo. 
Producto de estos cambios en la comprensión del folclor, parece que el concepto de autenticidad cede su lugar al de legitimidad: la discusión se mueve desde las "espontáneas" condiciones de producción de un contenido a la modelada construcción de un estilo apropiado para aquel. En último término, una vez que el contenido viene dado por sí solo (de la cultura doméstica de los niños), la autenticidad solo puede medirse por el estilo de la expresión; así nos explicamos la insistencia de Lenz en este concepto durante su "segunda etapa" (desde "Un grupo de consejas..."). Lenz comprende el estilo como la dimensión de la gramática referida a la apropiación afectiva del lenguaje, esa dimensión en que el individuo expresa una sensibilidad mediante la lengua (1920a: 42-44). A diferencia de como lo sostiene, la imaginación popular y sus restos no pueden trabajar solos si quieren ser auténticos: el profesor debe encauzar la expresión nacional para que el estilo calce con el contenido. La sobriedad y la fidelidad a un contenido previamente dado son las claves de un estilo que se entiende como transparente, inocente, especie de grado cero de la escritura (Barthes 2003) en que, sin embargo, reside el color y personalidad de la lengua nacional.

El estilo, garante de la autenticidad, es traspasado como norma desde el folclor a la expresión nacional. Retomemos una pregunta planteada más arriba: ¿cuáles son los alcances de este movimiento en el aula? Y es que la escuela tiene, ante todo, un fin civilizador y disciplinador; además de asegurar la sana (autorre)producción de lo nacional, también debe adiestrar en la lectura de los "buenos autores" y la adopción paulatina del lenguaje literario, valorado "como la espresion más lejitima para los pensamientos del pueblo chileno" (Lenz 1899a: 15). Ese es el difícil equilibrio que Lenz debe mantener en el aula: ¿cómo asegurar la pervivencia del lenguaje vulgar (devenido juez de sí mismo) y al mismo tiempo la educación creciente de la población, que representa la lengua literaria? Recordando la metáfora de la máquina de escribir de nuestro epígrafe, ¿cómo aprender a colorear la escritura sin fundir dos colores en uno?

En Sobre el estudio de idiomas. Cartas al señor don Julio Saavedra Molina (1918), Lenz se refiere largamente a la literatura que se debe leer en la enseñanza escolar y al tipo de lectura adecuada: una lectura cultural, basada en la valoración sobre todo moral, ideática y estética de la obra, que represente la cultura nacional en un momento histórico (Lenz 1918: 244-250). En esta carta, dedicada a los métodos de enseñanza de lenguas extranjeras, explica que las naciones americanas, por su compleja situación colonial, no poseerían una lengua propia que guarden como su patrimonio nacional (248); de ahí que el profesor deba servirse de toda la literatura moderna que esté a su alcance. Las naciones europeas, recuérdese, habían 
formado sus lenguas literarias "sobre base lingüística natural, pero por razones históricas de política" (Lenz 1979 [1905-1910]: 11), es decir, a partir de la selección de rasgos hallados en un tesoro común de un conjunto de dialectos. El español de Chile no constituiría una lengua propia porque no ha respondido a este proceso formativo. Con todo, lo más interesante es que Lenz sugiere una compensación que sería fiel a cierta unidad históricocultural de la lengua española. En este punto, es inequívoca la promoción de un proyecto pancastellano ( $c f$. Soto 2016) mediante el cual Lenz pretende salvar la anomalía constructiva de la historia y literatura chilenas:

en la enseñanza del castellano en Chile debe considerarse la literatura española e hispano-americana como una unidad, lo que no escluye, por supuesto, que se les conceda un lugar preferente a los autores españoles, como Ercilla, por ejemplo, estrechamente relacionados con la historia de Chile, i que a un autor chileno, que en España quizá seria uno entre muchos [!], se le estudie con el mismo detenimiento i cariño que los escritores sobresalientes. (Lenz 1918: 248, énfasis nuestro)

La falta de autenticidad de la cultura chilena, en tanto, es explicitada páginas antes: No olvidemos que el alumno chileno en su lengua patria tiene sólo acceso a la cultura española; en ella i en la historia nacional se funda la educacion del ciudadano, que se completa debidamente en las clases de instrucción cívica. Pero naciones tan jóvenes como Chile no pueden tener una cultura especifica i tienen que asimilarse la cultura mundial moderna que se halla espresada de la manera mas perfecta en las literaturas escritas en las tres lenguas estranjeras que se estudian en el liceo [inglés, francés y alemán]. (Lenz 1918: 245-246, énfasis nuestro)

La cultura popular es donde la cultura chilena se fundaría y donde además una auténtica lengua literaria hallaría su sostén y permanente renovación. Es por ello que Lenz rescata la figura del roto, para transfomar no solo el lenguaje literario sino también la lengua literaria. Como ha precisado Guillermo Soto (2016: 220) en un notable artículo sobre las ideas pedagógicas de Lenz, el alemán resume en el término "lengua literaria" (lo que hoy llamamos estándar) la suma de (a) el "lenguaje nacional" (cotidiano, culto y anclado en la vida pública) y (b) la capa superior a aquel, el "lenguaje [o estilo] literario", o sea, el de los "buenos autores"; ahora bien, el sentido de esta frase se definirá de acuerdo con lo que es efectivo en el uso local actual (Lenz 1979 [1910]: 7, 12-13). La lengua literaria, sin embargo, y como vimos antes, se encuentra con el lenguaje vulgar en la escuela. La valoración de Lenz de lo popular no redunda en un plegarse pasivo de esa variedad a la literaria, sino que esa debe fomentarse en paralelo y aportar a la transformación de 
la literaria ${ }^{37}$. El lenguaje nacional será un espacio de negociación entre el estilo modelado que proviene del lenguaje vulgar y la variedad usada por la población culta, a la que una mayoría adhiere por el uso y que está en contacto con los estilos de otras variedades castellanas, sobre todo la peninsular.

De esta manera, Lenz promueve el lenguaje vulgar no para alzarlo como lengua nacional en sí misma, sino para que sirva de contraparte a la asimilación de la cultura mundial y alimente de continuo a las variedades "superiores" de lengua, les irradie su autenticidad perenne y cambie el color de su escritura ${ }^{38}$. Únicamente el rescate de las formas tradicionales en la lengua vulgar permitiría proyectar una "cultura específica", tanto en sentido diacrónico (relación con la historia propia) como sincrónico (relación actual con otras naciones). En "Un grupo de consejas chilenas", luego de referirse a la "madre patria España" (149), declara que: "el cultivo i la relijiosa conservación de todos los productos del alma nacional [...] de su rica literatura oral vertida en sus cuentos i sus cantos, preparan el terreno en que crecerá lozana, sin abonos artificiales, la delicada planta del patriotismo!" (Lenz 1912: 149-150, énfasis nuestro). Bien podría reemplazarse "del patriotismo" por "de la lengua literaria", pues Lenz entiende que la lengua vulgar debe ser siempre el suelo de la literaria, tal como en el viejo continente: "en Europa el habla del pueblo indocto es la madre de la lengua literaria" (Lenz 1893b: 38), lengua artificial pero legitimada por una historia políticocultural.

\section{BALANCE Y CONCLUSIONES}

En este recorrido, hemos intentado mostrar algunas tensiones que atraviesan el pensamiento de Rodolfo Lenz acerca del folclor, considerando sus labores como científico y como agente estatal. Para ello, hemos visto que el folclor sirve a Lenz en dos sentidos políticos distintos: en tanto producción popular

\footnotetext{
37 Deducimos entonces que el hincapié de Lenz en la lectura cultural de los clásicos castellanos debe entenderse sobre todo desde su valor histórico-cultural (e.g., Lenz 1920a: 26) y no como norma lingüística vigente en la contemporaneidad. Es en ese sentido que aporta a la lengua literaria.

38 En el texto que comentamos - la carta a Julio Saavedra Molina-Lenz no hace referencia al folclor, pero sí a los ejercicios que se deben dar a los niños, como la composición libre de que ya hablamos (Lenz 1918: 251-255).
} 
estudiable, a partir de la cual se constituye un archivo nacional, y en tanto factor clave para la transformación de una categoría tan relevante como la de lengua literaria. En este sentido, hemos planteado que el espacio de la escuela sirve como puente entre las aspiraciones científicas y las obligaciones pedagógicas del alemán, aun cuando el conjunto de creencias sobre la lengua nacional es previo y encuentra su origen en las discusiones sobre la autenticidad del folclor. Así, mientras en "Die echte Volkspoesie der Frauen" Lenz celebra la escritura silábica original de las cantoras, en "Un grupo de consejas chilenas" también encontrará utilidad en la imitación de la escritura hacia la pronunciación del habla vulgar, pero se identificará además con la guía modelar del profesor, que asoma como un fantasma detrás del folclorista. Esta relación espectral, sin embargo, da cuenta de hasta qué punto aquel espectro no se encuentra detrás del folclorista; más preciso sería hablar de una cohabitación problemática de las figuras del folclorista y del pedagogo en la del lingüista. Esta relación explica las dos formas de comprender el folclor en Lenz: la primera marcada por premisas aún muy románticas (inmediatez, espontaneísmo, oralidad) y la segunda norteada por una idea menos esencialista y más estratégica y moderna, tránsito desde el paradigma de la autenticidad al de la legitimidad.

Algunas de las creencias de Lenz no resisten el paso del tiempo; así, la oposición Naturpoesie/Kunstopoesie se quiebra en "Un grupo de consejas chilenas", pues la idea de artificialidad que la sustenta es deshecha al interrogar por la legitimidad y no tanto por la esencia. En este sentido, solo queda en pie la relación entre lengua vulgar y lengua literaria, dinámica no de oposición sino de convivencia en un sistema lingüístico diverso, en que una y otra son entendidas como variedades de lengua. El sentido de la legitimidad parece variar también, pues en el sistema clásico la lengua literaria resulta una formación natural de la lengua vulgar o dialecto, y por tanto su carácter artificial no se explica por su desconexión con la lengua cotidiana, sino por la representatividad postiza respecto de una zona caracterizada por una diversidad dialectal. Al ser históricamente motivada y contingentemente refrendada, sin embargo, esa lengua es legítima. Con todo, algo de romanticismo se cuela todavía en la creencia de que el único alimento nacional para el alma chilena es el dialecto: "El lenguaje del bajo pueblo, el dialecto, es la principal fuente de la cual se debe enriquecer el tesoro del idioma" (Lenz 1899a: 17). Dicho romanticismo se vuelve particularmente problemático cuando Lenz llega a trasladar características inespecíficas del folclor-como la sobriedad, que en cuanto tal estarían en todas las literaturas del mundo- al carácter del sujeto chileno.

Asimismo, de lo escrito se pueden extraer algunas diferencias relativas al lugar que ocupa el folclor chileno y el folclor mapuche en el archivo 
nacional. Si el mapuche está condenado a su desaparición y, por tanto, solo puede gozar de una sobrevida bajo la lupa del arqueólogo, el chileno no puede morir porque la especificidad de la cultura y de la lengua literaria nacional depende de él. Así, además de fomentarse su estudio, patrimonialización y archivación, se fomenta su valor de uso, su cultivo "al lado de la literatura artística de la lengua de Cervantes" (1912: 44). En esta desigual valoración de los derechos de cada cultura y del papel que ella debe desempeñar en la formación de una nacionalidad chilena, lo popular chileno funciona como especie de archivo del folclor mapuche, al portar en él ya las marcas fonéticas y léxicas de la lengua castellano-chilena. Así, entendemos las múltiples técnicas empleadas por Lenz en sus trabajos de campo y en sus argumentaciones sobre folclor como dispositivos de captación de la diferencia (transcripción y escritura fonéticas, diccionario, etc.), pero se deben diferenciar los tratamientos a que fueron sometidos, la asimilación que sufrieron y los productos que de ese trabajo se derivaron: el foclor mapuche se encerró en el museo y su auditorio fue erudito; el chileno vio la luz pública y fue difundido entre un público más amplio.

En contraste con el destino del folclor mapuche, el folclor chileno amplía su área de producción a un espacio expresivo pero también disciplinario, el aula. Este punto de confluencia tensiona la perspectiva del folclorista, quien parece renunciar a los modelos más cercanos al romanticismo para admitir la escritura (que el pedagogo exige) como vehículo válido de la expresión nacional. Sin embargo, del otro lado, la creencia del folclorista acerca de un carácter nacional se traspasa como norma al criterio modelador del pedagogo. El apego a esta norma es el único camino para asegurar la pervivencia de la variedad popular y para transformar la lengua literaria en una "lengua de cultura" con los mismos derechos que las europeas. En consecuencia, es en virtud del anudamiento entre los requisitos de autenticidad del folclor y el modelamiento del idioma patrio que podrían explicarse algunos de los cambios en las ideas lingüísticas de Lenz sobre ambas esferas. Este juego entre vasos comunicantes muestra al filólogo alemán enfrentado a deberes disciplinares y aspiraciones científicas no siempre encontradas, pero -lo que es más interesante- además da una idea de los esfuerzos invertidos en conciliarlas allí donde las aporías de su inevitable colonialismo se cruzan con su democrático fervor popular (que nos da lecciones hasta hoy).

Para dar con la autenticidad de la expresión nacional, Lenz traslada su atención desde el edificio de la lengua (su estructura) al estilo, comprendido como parte de la gramática y, por tanto, como uno de sus estratos. La autenticidad, antes relacionada con la inmediatez y la espontaneidad, se transforma en materia pasible de elaboración y corrección. Para Lenz, el estilo propio de la expresión auténtica está encadenado al impulso o 
necesidad expresiva interior, pero el problema es que solo puede verificar ese impulso de manera confiable en los niños (y no, por ejemplo, en los poetas impresos). La garantía de dicha autenticidad no puede residir entonces en un dato interior e inmaterial, sino que en una disposición particular de la materia lingüística, el estilo, ese que Lenz recoge del asombro infantil y alza como el común. Desde "Un grupo de consejas chilenas", Lenz sugiere que ese estilo legítimo es el único capaz de dar un color propio al español de Chile, pues responde a una historia cultural. Se trata de un color que primero fue hablado por analfabetos y luego manuscrito por escolares. Este tránsito de la palabra por distintas tecnologías culturales acaba en la imagen de la máquina de escribir del filólogo que nos sirve de epígrafe: una imagen que semeja un sueño, un sistema de la lengua en que ambos colores -lenguaje vulgar y lengua literaria-alternan pero comienzan a superponerse en virtud del estilo. Acaso el sueño de Lenz sea imaginar, más que un color, un barniz que dé brillo al edificio de la lengua criolla en el paisaje mecanografiado de las lenguas del mundo.

\section{REFERENCIAS BIBLIOGRÁFICAS}

Anatole, F. 2 nov. 1917. Conversando con el doctor Lenz. El Sur (Concepción).

Anderson, Benedict. 1993 [1983]. Comunidades imaginadas. Reflexiones sobre el origen y la difusión del nacionalismo. Trad. Eduardo L. Suárez. $2^{\mathrm{a}}$ ed. México: FCE.

Barthes, Roland. 2003 [1972]. El grado cero de la escritura, seguido de Nuevos ensayos críticos. Trad. Nicolás Rosa. Buenos Aires: Siglo XXI.

Bauman, Richard y Charles Briggs. 2003. Voices of modernity. Language ideologies and the politics of inequality. Cambridge: Cambridge University Press.

Bendix, REgInA. 1997. In search of authenticity. The formation of folklore studies. Wisconsin: The University of Wisconsin Press.

Bernaschina, Vicente. 2013. Rodolfo Lenz, 150 años en disputa con el imperio de la lengua. Universum 28/2: 117-138.

Внавна, Номі. 1994. The location of culture. London/New York: Routledge.

Cameron, Deborah. 1995. Verbal hygiene. The politics of language. London/New York: Routledge.

Certeau, Michel de, Dominique Julia y Jacques Revel. 2004. La belleza del muerto. La cultura en plural. Buenos Aires: Nueva Visión.

Chávez Fajardo, Soledad. 2011. Ideas lingüísticas de Lenz en los paratextos de su Diccionario etimológico de las voces chilenas derivadas de lenguas indigenas americanas: vigencia y urgencia en el español de Chile. Lenguas Modernas 38: 83-106.

Contreras, Constantino. 1989. Lengua y folklore en la obra de Rodolfo Lenz. Estudios Filológicos 24: 39-53.

Dannemann, Manuel. 1989-1990. Rodolfo Lenz, etnólogo y estudioso del folklore. Revista Chilena de Antropología 8: 77-92. 
2010. Tres buscadores de la chilenidad: Lenz, Laval y Vicuña Cifuentes. Anales de Literatura Chilena 14: 57-92.

Derrida, JAcQues. 1997. Mal de archivo. Una impresión freudiana. Trad. Paco Vidarte. Madrid: Trotta.

EnNis, JuAn Antonio. 2016. Rodolfo Lenz: economías de la lengua y políticas de la lingüística. Boletín de Filología LI/1: 117-145.

y Stefan Pfänder. 2013. Lo criollo en cuestión. Filología e historia. Buenos Aires: Katatay.

ERRINGTON, JoSEPH. 2008. Linguistics in a colonial world. A story of language, meaning, and power. Oxford: Blackwell.

Escudero, Alfonso. 1963. Rodolfo Lenz. Thesaurus (Bogotá), t. XVIII, pp. 445-484.

Ferreccio, Mario. 1979. Presentación. Diccionario etimológico de voces chilenas derivadas de lenguas indígenas americanas. Rodolfo Lenz. Edición dirigida por Mario Ferreccio. Santiago: Seminario de Filología Hispánica, Universidad de Chile.

Formigari, Lia. 2004. A history of language philosophies. Amsterdam/Philadelphia: John Benjamins.

GutiérReZ, José. 1920. El Doctor Rodolfo Lenz. Revista Chilena, t. IX, pp. 64-84.

HobsBawm, Eric. 2002 [1983]. La invención de la tradición. Ed. Eric Hobsbawm y Terence Ranger. Trad. Omar Rodríguez. Barcelona: Crítica.

Humboldt, Wilhelm von. Sobre la diversidad de la estructura del lenguaje humano y su influencia sobre el desarrollo espiritual de la humanidad. Trad. y pról. Ana Agud. Madrid: Anthropos, 1990 [1836].

KaINDL, RaImUnd. 1903. Die Volkskunde. Ihre Bedeutung, ihre Ziele und ihre Methode. Leipzig y Viena: Franz Deuticke.

Lenz, Rodolfo. 1893a. Enseñanza de idiomas estranjeros (francés, ingles i aleman). Anales de la Universidad de Chile 84: 245-256.

1893b. Nacionalidad y lenguaje. Revista Nacional: historia americana, literatura, jurisprudencia (Buenos Aires), t. XVII: 35-47.

1894. Ensayos filolójicos americanos I y II. Anales de la Universidad de Chile 87: 113-132; 353-367.

1895-1897. Estudios araucanos. Materiales para el estudio de la lengua, la literatura $i$ las costumbres de los indios mapuche o araucanos. Santiago: Imprenta Cervantes.

1899a. Memoria sobre las tendencias de la enseñanza del idioma patrio en Chile. Santiago: Imprenta Cervantes.

1899b. Proyecto de programa de castellano. Santiago: Imprenta Cervantes.

1909. Programa de la Sociedad de Folklore Chileno. Santiago: Imprenta y Encuadernación Lourdes.

1912 [1911]. Un grupo de consejas chilenas. Estudio de novelística comparada precedido de una introducción referente al oríjen i la propagación de los cuentos populares. Revista de Folklore Chileno 3/1-3: 1-152.

1918. Sobre el estudio de idiomas. Carta al señor don Julio Saavedra Molina. Anales de la Universidad de Chile 142: 173-239, 243-264.

1919 [1895]. Sobre la poesía popular impresa de Santiago de Chile: contribución al folklore chileno. Anales de la Universidad de Chile, Memorias científicas y literarias 144: 511-622.

1920a. La enseñanza del castellano y la reforma de la gramática. Santiago: Imprenta y Litografía Universo.

1920b. La oración y sus partes. Madrid: Revista de Filología Española. 
1924. La composición escolar en lengua patria. Santiago: Ediciones de la revista "Cultura".

1979 [1905-1910]. Diccionario etimológico de voces chilenas derivadas de lenguas indígenas americanas. Edición dirigida por Mario Ferreccio. Santiago: Seminario de Filología Hispánica, Universidad de Chile.

2003-2004. La auténtica poesía folclórica. La expresión poética y musical de las mujeres. Trad. Manuel Dannemann. Archivos del Folclore Chileno 12: 85-102.

NietzSChe, Friedrich. 1951 [1869]. Homero y la filología clásica. Obras completas. Tomo I. El origen de la tragedia y obras póstumas de 1869 a 1873. Traducción, introducción y notas de Eduardo Ovejero y Maury. $3^{\circ}$ ed., pp. 25-41. Buenos Aires: Aguilar.

1968. El crepúsculo de los ídolos. Trad. Pedro González Blanco. Buenos Aires: Ediciones del mediodía.

Ortiz, José Miguel. 2017. "El archivo colonial de la lengua nacional: el mapuzugun o araucano en la obra de Rodolfo Lenz". Inédito.

Pavez, Jorge. 2015. Laboratorios etnográficos. Los archivos de la antropología en Chile (1880-1980). Santiago: Ediciones Universidad Alberto Hurtado.

PAYÀs, GERTRUDIs. 2015. "Tan verídica como patriota": la pugna sobre traducción entre Rodolfo Lenz y Manuel Manquilef. Cuhso 25/2: 83-114.

Poblete, Juan. 2003. El castellano: la nueva disciplina nacional. Literatura chilena del siglo XIX: entre públicos lectores y figuras autoriales, pp. 209-266. Santiago: Cuarto Propio.

Reynolds, Leighton y Nigel Wilson. Copistas y filólogos. Trad. Manuel Sánchez Mariana. Madrid: Gredos, 1986.

Rojas, Darío. 2011. Voces usadas en Chile (1900): las cartas de Aníbal Echeverría y Reyes a Rodolfo Lenz. Onomázein 24: 349-361.

Salinas, Maximiliano. 2011. El amor en la poesía y canto popular de Chile. Un manuscrito inédito de Rodolfo Lenz: Die echte Volkspoesie. Dichtung und Musik der Frauen (1894). En Gloria Chicote y Barbara Göbel (eds.). Ideas viajeras y sus objetos. El intercambio cientifico entre Alemania y América austral, pp. 305-319. Madrid/Frankfurt am Main: Iberoamericana/Vervuert.

SÁnchez, Gilberto. 1992. La contribución del Dr. Rodolfo Lenz al conocimiento de la lengua y cultura mapuches. Boletín de Filología XXXIII: 273-299.

Santiago, Silviano. 2000 [1978]. O entre-lugar do discurso latinoamericano. Uma literatura nos trópicos. Ensaios sobre dependênca cultural, pp. 9-27. $2^{\mathrm{a}}$ ed. Rio de Janeiro. Santiago: Rocco.

2012b [1980]. A pesar de dependiente, universal. Una literatura en los trópicos. Ensayos de Silviano Santiago, pp. 97-110. Traducción, presentación y edición de Mary Luz Estupiñán y Raúl Rodríguez Freire. Santiago: Escaparate.

SchÜtz, Günther. 1976. Correspondencia de Rufino José Cuervo con Rodolfo Lenz. Epistolario de Rufino José Cuervo con filólogos de Alemania, Austria y Suiza, vol. I, pp. 499-559. Bogotá: Instituto Caro y Cuervo.

Soto, Guillermo. 2016. Rodolfo Lenz y la enseñanza del castellano como idioma patrio en Chile. Boletín de Filología 51(1): 211-238.

Steinthal, Heymann. 1855. Grammatik, Logik und Psychologie. Ihre Principien und ihr Verhältniss zu einander. Berlin: Dümmler. http://www.deutschestextarchiv.de/book/show/ steinthal_grammatik_1855

Subercaseaux, Bernardo. 2007. Historia de las ideas y de la cultura en Chile, tomo IV. Santiago: Universitaria.

Velleman, B. 2007. Las ideas lingüísticas y pedagógicas de Eduardo de la Barra y su polémica con Lenz y Hanssen. Contextos, estudios de humanidades y ciencias sociales 18: 179-193. 
2008. La imagen y los ecos del lingüista profesional: la correspondencia de Rodolfo Lenz. Revista de Lingüística Teórica y Aplicada 46/1: 11-28.

Wundt, Wilhelm. 1900. Völkerpsychologie: eine Untersuchung der Entwicklungsgesetze von Sprache, Mythus und Sitte. Erster Band. Die Sprache. Erster Theil. Lepizig: Wilhelm Engelmann. https://archive.org/details/vlkerpsychologi02wundgoog

1904. Völkerpsychologie: eine Untersuchung der Entwicklungsgesetze von Sprache, Mythus und Sitte. Erster Band. Die Sprache. Erster Theil. Lepizig: Wilhelm Engelmann. https://archive.org/details/vlkerpsycholog11wund 